\title{
Effect of ambient conditions on calibration of hand-held infrared radiothermometers
}

\author{
A Olufayo ${ }^{1}, \mathrm{C}$ Baldy $1^{\star}$, P Ruelle 2 \\ 1 INRA, Laboratoire d'Écophysiologie des Plantes sous Stress Environnementaux, 2, place Viala, F34060 Montpellier Cedex 1; \\ 2 CEMAGREF, Division de I'Irrigation, BP 5095, F34033 Montpellier Cedex 1. France
}

(Received 2 February 1993; accepted 15 September 1993)

\begin{abstract}
Summary - Hand-held infrared radiothermometers are frequently used in water stress studies and in the management of irrigation water to measure soil and plant canopy temperatures. Different models of these instruments are available but manufacturers' calibration methods are not the same. Five models of radiothermometers were compared during field experiments on water stress studies on grain sorghum and soybeans at Montpellier, France. The in situ recalibration method advocated by Verbrugghe and Guyot (1992) was used in the field. It was confirmed that field and laboratory calibration equations were not the same. The effects of the main climatic parameters influencing the performance of radiothermometers were examined. Consequences of calibration methods on the calculation of certain stress indices, especially the stress degree day (SDD), were also examined.
\end{abstract}

radiothermometer / calibration / stress degree day / ambient conditions / canopy temperature

\begin{abstract}
Résumé - Effet des conditions de milieu sur l'étalonnage de radiothermomètres portatifs. Les radiothermomètres portatifs sont fréquemment utilisés pour étudier le stress hydrique et gérer lirrigation en suivant les températures d'émission des sols et des plantes. Différents modèles de radiothermomètres sont disponibles mais les méthodes d'étalonnage des fabricants diffèrent entre elles. Cinq modèles de radiothermomètres ont été comparés entre eux dans des études au champ concernant des cultures de sorgho et de soja à Montpellier, France. La méthode d'étalonnage in situ préconisée par Verbrugghe et Guyot (1992) a été utilisée. II a ainsi pu être confirmé que les équations des étalonnages réalisés au laboratoire et au champ sont différentes. Les effets des principaux facteurs du climat qui influencent la réponse des radiothermomètres sur le terrain sont examinés. Leurs conséquences pour l'application des coefficients de correction à plusieurs indices de stress, et particulièrement au stress degree day (SDD) sont examinées aussi.
\end{abstract}

radiothermomètre / étalonnage / stress degree day (SDD) / condition du milieu / température du couvert

\section{INTRODUCTION}

Soil and plant canopy temperatures are easily and rapidly measured using the infrared thermometry method. High precision is frequently required of these measurements in agriculture but is difficult to obtain in the field (Graham et al, 1989). Although many models of infrared thermometers exist, most of them were originally designed for use in enclosed buildings or controlled environments. In consequence, chang- ing ambient conditions in the field affect their performance as confirmed by many authors (Fuchs and Tanner, 1966; Jackson and Idso, 1969; Graham et al, 1989; Wright, 1990; Wanjura and Upchurch, 1991; Verbrugghe and Guyot, 1992). Verbrugghe and Guyot (1992) showed that the calibration of hand-held infrared thermometers carried out inside and outside a laboratory were significantly different and therefore proposed a simple in situ method of recalibration in the field. Wanjura and Up-

* Correspondence and reprints 
church (1991) also investigated the effects of calibration method on 18 portable radiothermometers and found that there were significant differences in relative temperatures (that is, target minus infrared thermometer detector temperature) obtained with field and manufacturers' calibrations. They therefore concluded that individual and periodic recalibrations of these instruments were necessary for better accuracy. The instruments were calibrated in the laboratory by submerging each radiothermometer in a temperature-controlled water bath. In the field the calibration procedure involved holding a blackbody calibration standard, Everest Interscience Inc Model 1000 so that it filled the field of view of the instrument. In both cases the output voltages for temperatures over a certain range were measured. Fuchs and Tanner (1966) showed that the effects of radiation emitted by the surroundings and reflected from the target to the sensor can be accounted for if the emissivity is a constant over all wavelengths within the waveband interval of the measuring instrument. If this effect is accounted for, the error in the determinations of vegetal surface temperatures does not exceed $\pm 0.1^{\circ} \mathrm{C}$, if the calibration of the instrument is checked for zero offsets at the time of measurement, and $\pm 0.3^{\circ} \mathrm{C}$ otherwise (Fuchs and Tanner, 1966).

During $3 \mathrm{yr}$ of field studies of water stress in sorghum and soybean, accurate determination of soil and plant canopy temperatures has been our concern. Therefore, systematic recalibrations of radiothermometers were carried out during periods of experiments, at the beginning as well as at the end of growing season. This paper is an attempt to examine the propositions suggested by Verbrugghe and Guyot (1992) in the light of our data and to analyse the main climatic parameters which might influence performance of these instruments in the field. It also aims at examining the consequences of calibration methods on the calculation of certain indices, especially the stress degree day (SDD), which are used for predicting crop yields and in management of irrigation water.

\section{The working principle of infrared thermometry}

The general principle of infrared thermometry has been well described by many authors (Jackson et al, 1981; Wanjura and Upchurch, 1991;
Verbrugghe and Guyot, 1992). Infrared thermometers are equipped with an optical assembly which collects the infrared radiation from the object being measured (target) and focuses it on a small detector (fig 1). They also contain spectral filters generally allowing measurements between 8-14 $\mu \mathrm{m}$. The detector transforms the infrared flux into an electric signal which is then converted into a temperature reading. Two types of instruments are available: static (DC) and chopped (AC) radiometers. $A C$ radiometers are more stable than $D C$ radiometers because the chopper blades are used as a temperature reference. The signal delivered by the sensors of such radiometers is proportional to the difference between the radiance of the viewed target and that of the chopper. It does not depend on the sensor temperature. On the contrary, DC radiometers use only an internal compensation based on the measurement of the sensor temperature. Most field radiothermometers are DC radiometers with complementary capabilities such as digital output (RS 232 port), data storage, laser beam pointer, etc.

The measurement of the radiative temperature of a given target comprises 2 successive steps involving the detector (thermopile or thermistor bolometer) and the temperature sensor (thermistor) (Wanjura and Upchurch, 1991):

- the radiative flux exchange between the viewed target and the detector (fig 1) induces a change in the detector temperature which is translated into an electrical signal. In most cases the manufacturers assume a fifth-order polynomial equation relating this electric signal to the radiative temperature difference $\delta T$ existing between the target and the body of the detector $T_{d}$ for $D C$ radiometers;

- the temperature $T_{d}$ of the detector (or of the case of the detector) is determined with the help of a thermistor.

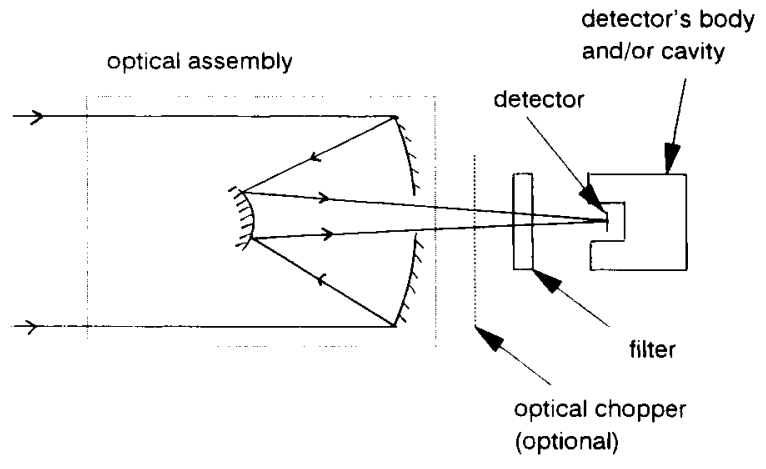

Fig 1. Optical system of a radiothermometer. 
Therefore the radiative temperature of the surface $\left(T_{\mathrm{s}}\right)$ becomes:

$$
T_{\mathrm{s}}=T_{\mathrm{d}}+\delta T \quad\left(\text { in }{ }^{\circ} \mathrm{C}\right)
$$

where $\delta T$ is the difference in temperature between the target and the detector.

Equation [1] shows that the error on $T_{\mathrm{s}}$ depends on the measurement errors on $T_{\mathrm{d}}$ and $\delta T$. The error on $T_{\mathrm{d}}$ is due to the internal temperature gradients existing between the detector, its cavity and its temperature sensor (Kalma et al, 1988). This error is strongly reduced when a chopper is used. As indicated by Verbrugghe and Guyot (1992) this error depends on the design of the radiothermometer, which can be more or less protected against external heating.

The error in $\delta T$ is due to the heating of the optical system (lenses and bandpass filter) which has to cut the incident solar short-wave radiation flux. If the temperature of the optical system components varies as a function of ambient shortwave radiation, a parasitic thermal radiation flux is superimposed to that coming from the target (Verbrugghe and Guyot, 1992). This can cause a variation in the calibration equation as a function of the experimental conditions.

The calibration equations of the radiothermometers available are expected to be linear. However slopes and intercepts depend on prevailing conditions at the time of measurement. What then are the main climatic variables that influence these coefficients and how?

\section{MATERIALS AND METHODS}

At the beginning of each growing season a number of radiothermometers are compared at the Laboratoire de Bioclimatologie, INRA, Avignon, France in order to check their thermal stability with time. The black body considered consists of 2 cones soldered at the base and lined with a special black paint ( $3 \mathrm{M}$ velvet coating 101-C10 black). In the field, the in situ calibration method suggested by Verbrugghe and Guyot (1992) and similar to that described by Berliner et al (1984) was used. Two well-stirred water baths at temperatures of $20^{\circ} \mathrm{C}$ and $40^{\circ} \mathrm{C}$ (which is the range of expected crop canopy temperature in the field, see fig $2 a, b)$ were viewed vertically by the radiothermometer. The calibration procedure consisted of taking surface water temperature readings of water baths before and after the usual field measurements of crop canopy temperature at solar noon. The readings of the radiothermometers were then compared with that of a reference thermometer. The emissivity of water was assumed to

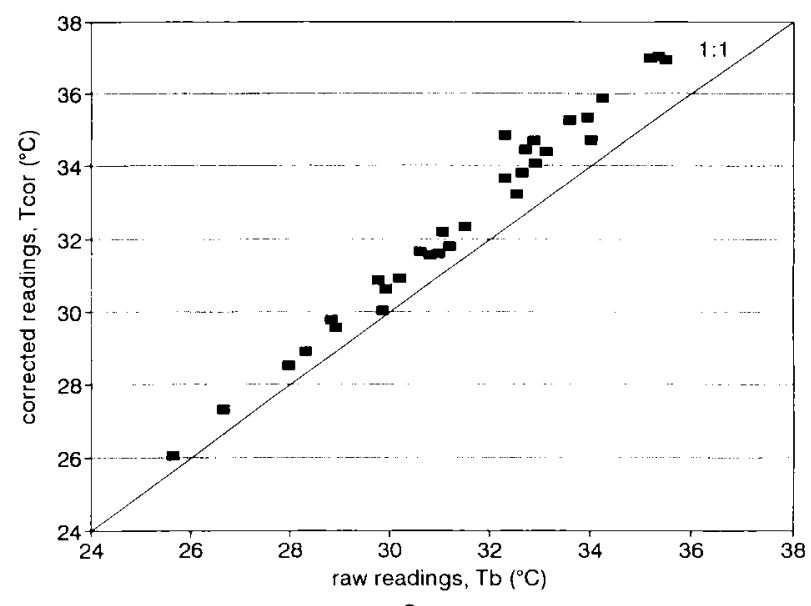

a

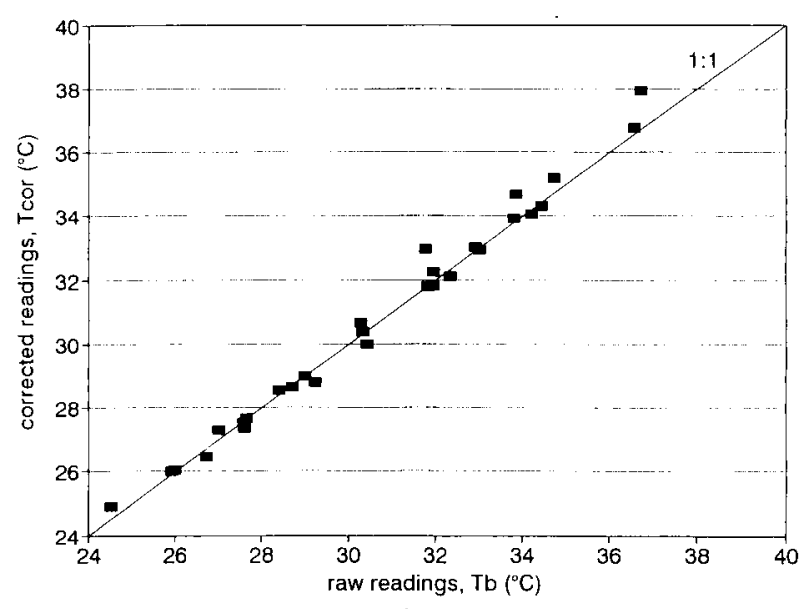

b

Fig 2. (a) Relationship between raw and corrected readings of Tasco THI300; (b) Relationship between raw and corrected readings of Everest 510.

be 0.98 (Robinson and Davies, 1972; Berliner et al, 1984; Verbrugghe and Guyot, 1992).

Three of these radiothermometers, namely, Everest 510B, Tasco THI 300 and Raytek PM3, were used in the field during water stress studies of sorghum and soybean at the Centre d'Étude de Machinisme Agricole du Génie Rural des Eaux et des Forêts (CEMAGREF) experimental station Lavalette, Montpellier. The data discussed in this paper concern a series of radiothermometer calibrations carried out in the laboratory in April 1991 and April 1992, and in the field during the monitoring of canopy temperature of grain sorghum and soybeans in Montpellier in 1991 (using Tasco THI300 and Everest 510). The monitoring started in the field when sorghum (or soybean) had a leaf area index (LAI) of 2 (soil was well covered) up to a LAI of about 5 . These readings were taken at solar noon during clear days and in a number of differentially irrigated plots. Canopy temperature was computed as the average of 10 readings $(\mathrm{Ol}-$ ufayo et al, 1993). 


\section{RESULTS AND DISCUSSION}

Since the relationship between radiothermometer readings and true "black-body" temperature is expected to be linear, calibration equations are expressed as linear models:

$$
T_{\text {ref }}=a T_{\mathrm{b}}+b \quad\left(\text { in }^{\circ} \mathrm{C}\right)
$$

where: $T_{\text {ref: }}$ reference temperature of black body; $T_{b}$ : radiothermometer readings; and $a, b$ : slope and intercept.

For example, figure 3 is a calibration curve for Tasco THI30O using the black body in the laboratory at Avignon (whose emissivity is assumed to be 1.00 ). The radiothermometer body was maintained at laboratory room temperature (that is, about $20^{\circ} \mathrm{C}$ ). The temperature at the point of intersection with the diagonal is about $25^{\circ} \mathrm{C}$. In other words, the radiothermometer underestimates the black body's temperature below this point and vice versa. Similar points of intersection were observed when all field calibration data were regrouped. Table I contains a summary of calibration equations of 8 radiothermometers obtained 10 April, 1991 and 20 April, 1992. A high degree of correlation was observed in all cases (coefficient of correlation $r^{2}>0.989$ ).

It was observed that the coefficients of the calibration equations obtained in the laboratory and in the field were different irrespective of the model of the instrument. Hence there is need to carry out a periodic recalibration of each instrument used, in similar conditions to the time of measurement. This confirms the observations made by Verbrugghe and Guyot (1992). Higher values

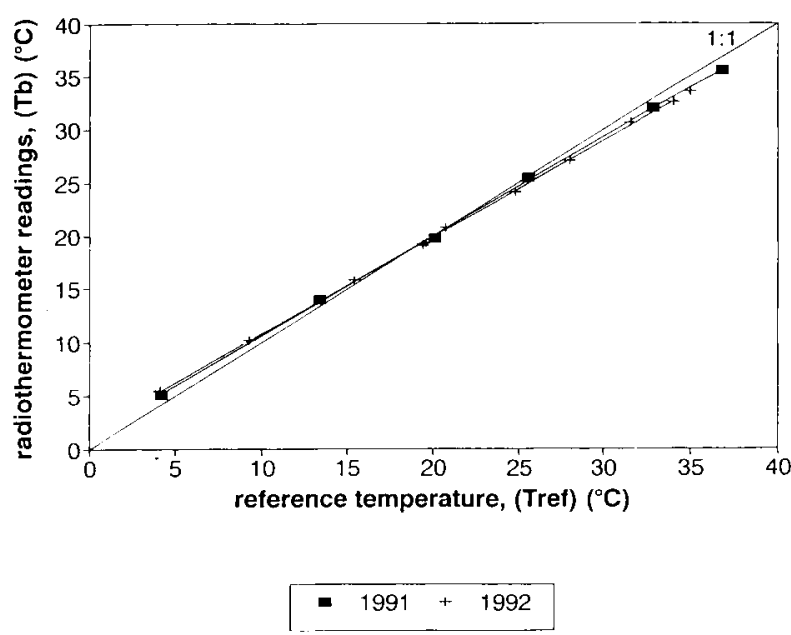

Fig 3. Calibration curves of Tasco THI300 in April 1991 and April 1992. of the standard error of the estimates were observed in the field. This could be explained by changing conditions in the field as opposed to stable conditions inside a laboratory.

\section{Consequences on the calculation of stress indices}

Field radiothermometer readings were corrected using calibration equations (eq [2]) obtained in the field (see above). Measurement error, $E_{r r}$, can be defined as the difference between corrected radiothermometer readings $T_{\text {cor }}$ (from daily field calibrations) and uncorrected radiothermometer readings $T_{\mathrm{b}}$ (that is, $E_{\mathrm{rr}}=T_{\text {cor }}-T_{\mathrm{b}}$ ). In this experiment the range of $T_{b}$ was between $25^{\circ} \mathrm{C}$ and $38^{\circ} \mathrm{C}$ (table II) and $E_{\mathrm{rr}}$ varied between $0^{\circ} \mathrm{C}$ and $4^{\circ} \mathrm{C}$ (Wright 1990 recorded a range of $-5^{\circ} \mathrm{C}$ to $+8^{\circ} \mathrm{C}$ for an unchopped model of radiothermometer over a wide range of its body temperature). The effect of this discrepancy can be very significant in the estimation of certain indices based on canopy temperature. An example is the stress degree day defined by Idso et al (1977) as:

$$
\mathrm{SDD}_{i}=\left(T_{\mathrm{C}}-T_{\mathrm{a}}\right)_{i} \quad\left(\text { in }^{\circ} \mathrm{C}\right)
$$

where $T_{\mathrm{c}}$ is the canopy temperature and $T_{\mathrm{a}}$ the air temperature measured around solar noon on day $i$. (A more detailed description of the experimental procedure for measurements of air and canopy temperature is given by Olufayo et al 1993.) The summation of stress degree day $(\Sigma S D D)$ over a given period is therefore expressed as:

$$
\sum \mathrm{SDD}_{i}=\sum\left(T_{\mathrm{C}}-T_{\mathrm{a}}\right)_{i} \quad\left(\text { in }{ }^{\circ} \mathrm{C} \cdot \text { day }\right)
$$

During this experiment $\Sigma$ SDD was calculated using only positive values of SDD (Jackson et al, 1977). It was initialised after a rainfall event greater than $10 \mathrm{~mm}$. The error in the calculation of $\Sigma$ SDD is cumulative and can therefore have a significant effect when used for timing of irrigation. In order to illustrate this point, the $\Sigma$ SDD of grain sorghum was estimated using corrected and uncorrected values of canopy temperature (monitored with Tasco THI300). As shown in figure 4 , a difference of $40^{\circ} \mathrm{C} \cdot$ day was observed in the 2 values of $\Sigma$ SDD in the stressed plot 75 days after emergence. Under Montpellier conditions a threshold value of $35^{\circ} \mathrm{C} \cdot$ day for irrigation appeared appropriate for optimum yield. Hence if 
Table I. Calibration coefficients of different radiothermometers determined in the laboratory with a temperaturecontrolled black body.

\begin{tabular}{|c|c|c|c|c|c|}
\hline Type of portable radiothermometer & Date & $a^{*}$ & $b^{*}$ & $r^{2 *}$ & $n$ * \\
\hline Everest $510 \mathrm{~B}$ & $\begin{array}{l}\text { April } 1991 \\
\text { April } 1992\end{array}$ & $\begin{array}{l}0.993 \\
1.029\end{array}$ & $\begin{array}{r}0.428 \\
-0.486\end{array}$ & $\begin{array}{l}0.9998 \\
0.9997\end{array}$ & $\begin{array}{l}6 \\
9\end{array}$ \\
\hline Everest 110 (No 1) & April 1991 & 1.008 & -0.025 & 0.9997 & 6 \\
\hline Everest 110 (No 2) & April 1991 & 1.001 & 0.368 & 0.9998 & 6 \\
\hline Tasco (No 080) & $\begin{array}{l}\text { April } 1991 \\
\text { April } 1992\end{array}$ & $\begin{array}{l}1.072 \\
1.103\end{array}$ & $\begin{array}{l}-1.325 \\
-1.882\end{array}$ & $\begin{array}{l}0.9999 \\
0.9997\end{array}$ & $\begin{array}{r}6 \\
13\end{array}$ \\
\hline Tasco (No 012) & $\begin{array}{l}\text { April } 1991 \\
\text { April } 1992 \\
\text { April } 1991\end{array}$ & $\begin{array}{l}1.060 \\
0.075 \\
0.947\end{array}$ & $\begin{array}{r}-1.267 \\
-1.269 \\
2.266\end{array}$ & $\begin{array}{l}0.9999 \\
0.9995 \\
0.9950\end{array}$ & $\begin{array}{r}6 \\
13 \\
8\end{array}$ \\
\hline Agema Raytek (No 439) & April 1992 & 1.005 & 0.464 & 0.9997 & 13 \\
\hline Raytek (No 440) & April 1992 & 1.020 & -0.080 & 0.9996 & 13 \\
\hline
\end{tabular}

- $a, b$ : slope and intercept; $r^{2}$ : correlation coefficient; $n$ : number of data points.

Table II. Variables tested in the stepwise multiple regression procedure.

\begin{tabular}{|c|c|c|c|c|c|}
\hline Variable & Symbol & Units & Range & Mean & $s d$ \\
\hline \multicolumn{6}{|l|}{ Dependent: } \\
\hline Measurement error & $E_{\mathrm{rr}}$ & ${ }^{\circ} \mathrm{C}$ & $0.03-3.40$ & 1.07 & 0.69 \\
\hline \multicolumn{6}{|l|}{ Independent: } \\
\hline Raw radiothermometer reading & $T_{\mathrm{b}}$ & ${ }^{\circ} \mathrm{C}$ & $25.6-37.9$ & 30.88 & 2.93 \\
\hline Air temperature & $T_{\mathrm{a}}$ & ${ }^{\circ} \mathrm{C}$ & $25.8-35.6$ & 30.67 & 2.90 \\
\hline Vapour pressure deficit & VPDD & $\mathrm{KPa}$ & $0.9-4.3$ & 2.71 & 0.91 \\
\hline Solar radiation & $R g$ & $\mathrm{~W} / \mathrm{m}^{2}$ & $406-972$ & 821 & 133 \\
\hline Wind speed & $\tilde{W}$ & $\mathrm{~m} / \mathrm{s}$ & $1.1-3.6$ & 1.94 & 0.56 \\
\hline
\end{tabular}

this recommendation had been followed using the raw data from the radiothermometer, it would had been done $6 \mathrm{~d}$ later than the data obtained from corrected values. If this period fell at a critical stage for sorghum, it would lead to a decrease in grain yield of up to $30-40 \%$ (Langlet, 1973).

This example shows the relativity of the stress degree day concept. The threshold value for irrigation can vary as a function of the radiothermometer used. Field calibration appears to be a better way of obtaining reliable data. It is also necessary to emphasize that the accuracy of oth- er indices like the crop water stress index (CWSI) (Jackson et al, 1981) based on the difference between canopy temperature $\left(T_{c}\right)$ and air temperature $\left(T_{\mathrm{a}}\right)$ would seriously be affected if uncorrected values were used (Campbell and Norman, 1990). The CWSI can be defined as (Jackson et al, 1988):

$$
\text { CWSI }=\frac{\left(T_{\mathrm{c}}-T_{\mathrm{a}}\right)-\left(T_{\mathrm{c}}-T_{\mathrm{a}}\right)_{\|}}{\left(T_{\mathrm{c}}-T_{\mathrm{a}}\right)_{\mathrm{ul}}-\left(T_{\mathrm{c}}-T_{\mathrm{a}}\right)_{\|}}
$$

where $\left(T_{\mathrm{c}}-T_{\mathrm{a}}\right)$ is the measured temperature difference. The upper limit of $T_{\mathrm{c}}-T_{\mathrm{a}},\left(T_{\mathrm{c}}-T_{\mathrm{a}}\right)_{\mathrm{ul}}$ 


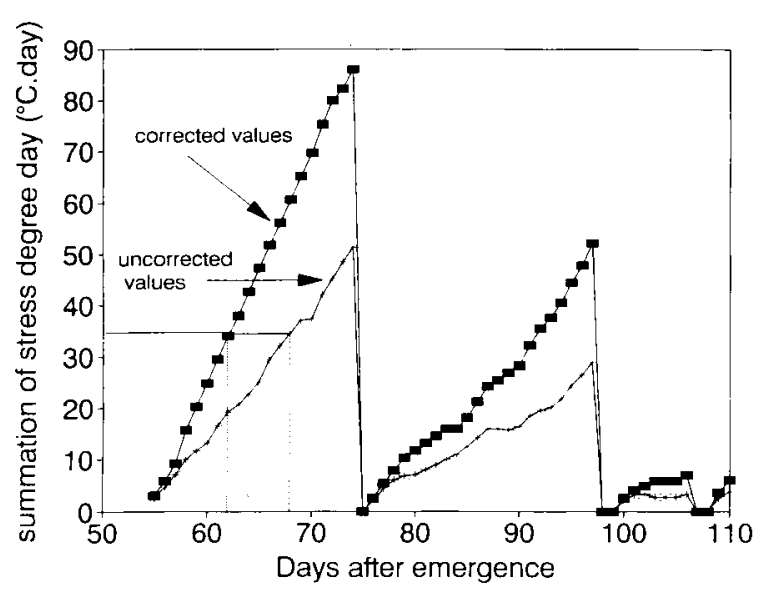

Fig 4. Summation of stress degree day of a stressed sorghum canopy.

represents a c completely stressed, nontranspiring canopy. The lower limit, $\left(T_{\mathrm{c}}-T_{\mathrm{a}}\right)_{11}$, represents a non-stressed canopy transpiring at potential rate.

The maximum amplitude of $\left(T_{\mathrm{c}}-T_{\mathrm{a}}\right)$ for sorghum in the Mediterranean climate is only a few degrees Celsius (about $10^{\circ} \mathrm{C}$ ). An error of about $2-3^{\circ} \mathrm{C}$ on the estimation of canopy temperature has a direct consequence on the calculation of CWSI using either empirical (Idso et al, 1981) or theoretical methods (Jackson et al, 1981).

\section{Effects of ambient conditions}

Figure 5 illustrates the influence of some ambient conditions (air temperature $\left(T_{\mathrm{a}}\right)$, solar radiation $(R g)$, and wind speed $(W)$ ) measurement errors on stressed sorghum canopy temperature. The climatic data used were obtained from an automatic meteorological station (CIMEL Co) located $120 \mathrm{~m}$ from the experimental site and correspond to average values during the time of usual field measurement at solar noon (that is, $11.00 \mathrm{~h}-12.00 \mathrm{~h}$ ). Measurement errors (obtained using Tasco THI300) were estimated by correcting the indicated temperatures using the daily in situ calibration equations. As shown in figure 5, there appeared to be definite trends in the relationship between ambient air temperature $\left(T_{\mathrm{a}}\right)$, wind speed and measurement error. During hot weather the radiothermometer body temperature rises and hence heats up the detector which results in a measurement error as discussed earlier. In the case of wind speed, there appears to be an inverse relationship: strong
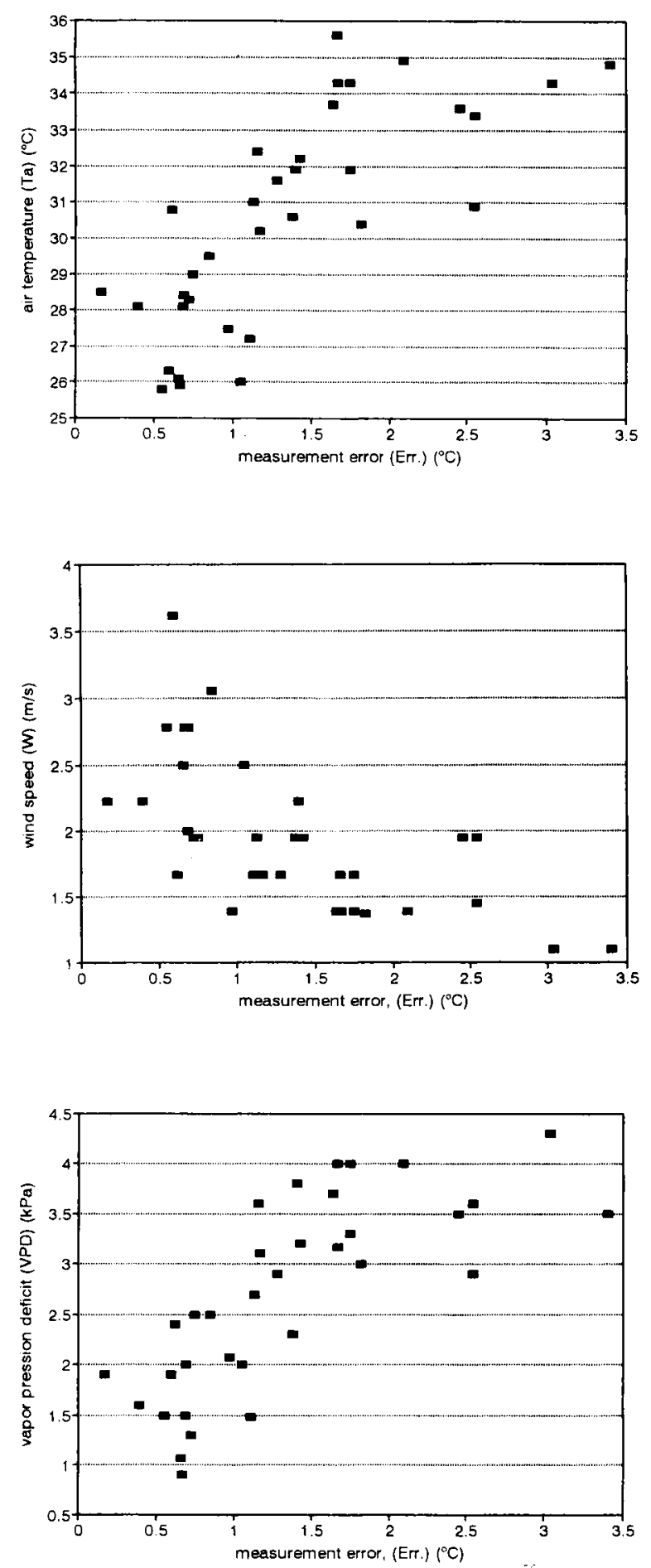

Fig 5. Relationship between measurement error and climatic variables.

wind produces a cooling effect thereby reducing the instrument body's temperature. There is no distinct trend in the case of solar radiation since measurements are usually carried out during bright sunny days. Similar observations were made from data in a well-watered plot. 


\section{Correlation between variables}

The stepwise multiple linear regression analysis technique was employed in order to determine the most important variables influencing the measurement error (Scherrer, 1984). The variables tested are summarized in table II. The matrix of correlation between variables are presented in table III. The measurement error $E_{\mathrm{rr}}$ used is based on daily corrected canopy temperature, $T_{\text {cor }}$ and daily raw readings $T_{b}$, of both stressed and well-watered sorghum plots (using Tasco THI 300). $E_{\mathrm{rr}}$ was highly correlated with radiothermometer raw readings and air temperature and least correlated with solar radiation. Although high correlation was observed between the measurement error and vapour pressure deficit (VPD), the latter would not be a pertinent parameter influencing the infrared thermometer measurement. This factor varies with air temperature as indicated by its high correlation $T_{\mathrm{a}}$. The measurements are performed within the atmospheric window and it is evident that variation of water content of the optical path between the canopy and the radiometer (few meters) would not have significant effect on the radiation flux measured (Jackson et al, 1981). It is important to note that $T_{\mathrm{b}}$ is highly correlated with $T_{\mathrm{a}}$.

\section{Multiple linear regression}

The stepwise regression procedure established that the raw radiothermometer readings and wind speed explained $66 \%$ of the measurement error. Other variables were not significant. The resulting relationship is as follows:

$$
\begin{aligned}
& \left.E_{\mathrm{rr}}=-3.558+0.165 T_{\mathrm{b}}-0.242 W \text { (in }{ }^{\circ} \mathrm{C}\right) \quad \text { [6] } \\
& r=0.801 ; n=73 .
\end{aligned}
$$

The statistical properties of this regression are shown in table IV. The influence of air temperature has been incorporated in the sorghum canopy temperature $\left(T_{b}\right)$. As indicated earlier, the 2 variables were highly correlated.

The full regression analysis between daily measurement error, $E_{r r}$, and raw readings and climatic variables gives:

$$
\begin{aligned}
& E_{\mathrm{rr}}=0.17 T_{\mathrm{b}}-0.09 T_{\mathrm{a}}+0.32 V P D-0.001 R g \\
& -0.26 W-1.23 \\
& \mathrm{n}=74 ; r=0.817 \text {. }
\end{aligned}
$$

Although the VPD parameter does not have a direct effect on the measurement of surface temperature, it influences the atmospheric longwave radiation as shown by the following equation:

$$
R_{\mathrm{a}}=1.24(\mathrm{e} / T)^{1 / 7} \sigma T^{4} \quad \text { (Brutsaert, 1975) }
$$

where $R_{\mathrm{a}}\left(\mathrm{W} / \mathrm{m}^{2}\right)$ is atmospheric long-wave radiation, $T(\mathrm{~K})$ is air temperature, $e$ is vapour pressure $(\mathrm{Pa})$ and $\sigma$ is the Stefan Boltzmann constant $\left(\mathrm{W} / \mathrm{m}^{2} \mathrm{~K}^{4}\right)$.

Fuchs and Tanner (1966) and Jackson (1982) showed that atmospheric long-wave radiation that is partly emitted by the surroundings influences the accuracy of measurements of surface temperature.

Similar analyses were carried out with data

\begin{tabular}{|c|c|c|c|c|c|c|}
\hline & $E_{r r}$ & $T_{b}$ & $\mathrm{~T}_{a}$ & VPD & $\mathrm{Rg}$ & $W$ \\
\hline $\begin{array}{l}E_{\mathrm{rr}} \\
T_{\mathrm{b}} \\
T_{\mathrm{a}} \\
V P D \\
R g \\
W\end{array}$ & 1.000 & $\begin{array}{l}0.780^{\star *} \\
1.000\end{array}$ & $\begin{array}{l}0.618^{\star \star} \\
0.721^{\star \star} \\
1.000\end{array}$ & $\begin{array}{l}0.604^{\star \star} \\
0.637^{\star \star} \\
0.918^{\star \star} \\
1.000\end{array}$ & $\begin{array}{l}0.142 \\
0.240^{*} \\
0.249^{*} \\
0.356^{\star *} \\
1.000\end{array}$ & $\begin{array}{c}-0.475^{\star \star} \\
-0.397^{\star \star} \\
-0.607^{\star \star} \\
-0.535^{\star \star} \\
-0.015 \\
1.000\end{array}$ \\
\hline
\end{tabular}
obtained using the Everest 510 . There was no influence of climatic variables in the calculated measurement errors:

$$
\begin{aligned}
& E_{\mathrm{rr}}=0.03 T_{\mathrm{b}}-0.008 T_{\mathrm{a}}+0.043 V P D+0.0001 R g \\
& -0.023 W-0.736 \\
& n=29 ; r^{2}=0.10 \text {. }
\end{aligned}
$$

Table III. Matrix of correlation between variables.

\footnotetext{
* Significant correlation at $0.05>P>0.01$; ${ }^{* \star}$ significant correlation at $P<0.01$.
} 
Table IV. Regression of $E_{\mathrm{rr}}$ on $T_{\mathrm{b}}$ and $W$.

Variable Coefficient Standard error Student t-value

\begin{tabular}{lrrr}
\hline Constant & -3.558 & 0.664 & -5.357 \\
$T_{\mathrm{b}}$ & 0.165 & 0.018 & 9.007 \\
$W$ & -0.242 & 0.096 & -2.520
\end{tabular}

Degrees of freedom: 70 ; residual mean square: 0.1755 ; R squared: 0.6415 .

This is explained by the greater accuracy observed using Everest 510 as compared to Tasco THI300. (The root-mean-square errors in the measurement of surface temperature using TasCo THI300 and Everest 510 are 1.27 and 0.42 , respectively.) Everest 510 is more complex instrument which self-calibrates using a mechanical chopper of known temperature and emissivity. The chopper moves in a regular manner in front of the instrument's viewing aperture. Similar observations were made by Wright (1990) who compared the performance of unchopped and chopped infrared thermometers under conditions of changing ambient temperature. The chopped model gave better accuracy and there was high correlation between measurement error and instrument body temperature in the unchopped model. A correction based on empirical function between measurement error and instrument body temperature was proposed for the unchopped model.

It may also be possible to carry out similar corrections using the empirical function such as equations [6] or [7] above. It is evident that the empirical relationship would only be valid under conditions to which it has been adjusted and for the specific radiothermometer. The establishment of such empirical functions for each instrument (which is not the aim of this paper) should take into account the representativity of climatic data used (ie instantaneous or averaged data).

\section{CONCLUSION}

We have examined the problem of recalibration of 5 models of radiothermometers in the laboratory and in the field during water stress studies of certain crops at Lavalette, Montpellier. There were significant differences in the calibration equations obtained. These discrepancies were due to differences in each instrument's mode of construction and to the effects of environmental conditions on calibration equations. The magnitude of error observed in AC-type radiothermometers (with choppers) was less than that of DC radiothermometers (without choppers). In the case of the DC-type radiothermometers (Tasco THI300) examined in this paper, certain climatic variables such as air temperature, vapour pressure deficit and wind speed had varied effects on its in situ calibration equations.

A direct consequence of this is the relativity of the water stress indices concepts based on canopy temperature (eg SDD, CWSI). The importance of reliable data in the calculation of these indices, which are often used in deciding irrigation, cannot be over-emphasized.

Hence there is a need for periodic, and individual recalibration of these instruments in order to improve their precision. The in situ method of calibration advocated by Verbrugghe and Guyot (1992) is very simple and practical and would not present any problems to farmers.

\section{ACKNOWLEDGMENTS}

This work is a part of a joint research project between the INRA Laboratoire d'Écophysiologie des Plantes sous Stress Environnementaux (LEPSE) and the Centre d'Étude du Machinisme Agricole, du Génie Rural, des Eaux et des Forêts (CEMAGREF) Montpellier, France on arid climatic effects on crops. We thank $H$ Nicolas and $\mathrm{S}$ Holmes for their useful suggestions. We are also grateful to A Boutland for correction of the English and to the students who participated in data collection. The authors can furnish the address of the manufacturers of radiothermometers.

\section{REFERENCES}

Berliner P, Oostherhuis DM, Green GC (1984) Evaluaton of the infrared thermometer as a crop stress detector. Agric For Meteorol 31, 219-230

Brutsaert W (1975) On a derivable formula for longwave radiation from clear skies. Water Resour Res $11,742-744$

Campbell GS, Norman JM (1990) Estimation of plant water status from canopy temperature: analysis of the inverse problem. In: Applications of remote sensing in agriculture (MD Steven, JA Clark, eds). Butterworth, London, 225-271

Fuchs M, Tanner CB (1966) Infrared thermometry of vegetation. Agron J 58, 597-601

Graham MED, Thurtell GW, Kidd GE (1989) Calibration of a small infrared sensor for measuring leaf temperature in the field, Non-steady-state conditions. Agric For Meteorol 44, 295-305 
Idso SB, Jackson RD, Pinter PJ, Reginato RJ, Hatfield $\mathrm{JL}$ (1981) Normalising the stress degree day for environmental variability. Agric Meteorol 24, 45-49

Idso SB, Jackson RD, Reginato RJ (1977) Remote sensing of crop yields. Science 196, 19-25

Jackson RD, Kustas WP, Choudhury RJ (1988) A reexamination of the crop water stress index. Irrig $\mathrm{SCi}$ 9, 309-317

Jackson RD (1982) Canopy temperature and crop water stress. In: Advances in Irrigation (D Hillel, ed) vol 1, Acad Press. NY 43-85

Jackson RD, Idso SB, Reginato RJ, Pinter Jr PJ (1981) Canopy temperature as a crop water stress indicator. Water Resour Res 17, 1133-1138

Jackson RD, Reginato RJ, Idso SB (1977) Wheat canopy temperature: a practical tool for evaluating water requirements. Water Resour Res 13, 651-656

Jackson RD, Idso SB (1969) Ambient temperature effects in infrared thermometry. Agron J 61, 324-327

Kalma JD, Alksnis H, Laughlin CP (1988) Calibration of small infrared surface temperature transducers. Agric For Meteorol 43, 83-98
Langlet A (1973) Effets de la sécheresse sur la croissance et la production du sorgho grain. Ann Agron 24 (3), 307-338

Olufayo A, Baldy C, Ruelle P, Konate J (1993) Diurnal course of canopy temperature and leaf water potential of sorghum (Sorghum bicolor L Moench) under a Mediterranean climate. Agric For Meteorol 64, 223-236

Robinson PJ, Davies IA (1973) Laboratory determinations of water surface emissivity. J Appl Meteorol $11,1391-1393$

Scherrer B (1984) Biostatistics. G Morin Editeur, Chicoutimi, Québec, Canada

Verbrugghe M, Guyot G (1992) Note sur l'étalonnage de radiothermomètres infrarouges portables. agronomie 12, 79-83

Wanjura DF, Upchurch DR (1991) Infrared thermometer calibration and viewing method effects on canopy temperature measurement. Agric For Meteorol 55, 309-321

Wright IR (1990) A laboratory calibration of infrared thermometers. Int J Remote Sensing 11, 181-186 